\title{
Transmedia Storytelling desde la ficción televisiva serial española: El caso de Antena 3
}

\author{
Francesc MAYOR MAYOR ${ }^{1}$ \\ f_mayor_mayor@hotmail.com
}

(Abstracts y palabras clave al final del artículo)

Enviado: 20 de abril de 2013

Evaluado: 30 de junio de 2013

Aceptado: 1 de agosto de 2013

\section{INTRODUCCION: EL TRANSMEDIA STORYTELLING}

Para conocer el origen y los matices que ha ido adquiriendo el término de narración transmediática o transmedia storytelling, el autor de referencia es, sin lugar a dudas, Henry Jenkins. El concepto de la narración transmediática "se incorporó al debate público en 1999, cuando el público y los críticos intentaban comprender el espectacular éxito de The Blair Witch Project, una película independiente de bajo presupuesto que se convirtió en una mina de oro" (Jenkins, 2008:107). La definición del mismo se demoraría unos años más, concretamente hasta 2003, y fue el propio Jenkins quien la dio a conocer en un artículo publicado en Technology Review.

En esta publicación expone que, en la forma ideal de la narración transmedia, cada medio hace lo que se le da mejor, de suerte que una historia puede presentarse en una película y difundirse a través de la televisión, las novelas y los cómics, mientras su mundo puede explorarse en los videojuegos. Cada entrada a la franquicia ha de ser independiente y posibilitar su consumo autónomo. Es decir, no es necesario haber visto la película para disfrutar del juego y viceversa (Jenkins, 2003).

Unos años más tarde, concretamente en 2007, formularía una definición más precisa de la narrativa transmedia: un proceso según el cual los elementos integrales de una ficción se dispersan sistemáticamente a través de múltiples canales de distribución con el propósito de crear una experiencia de entretenimiento unificada y coordinada. Lo ideal sería que cada medio hiciera una contribución exclusiva al desarrollo de la historia (Jenkins, 2007).

Entre todas las características que definen una producción transmedia, Jenkins resalta una: la participación de los públicos, de los fans en concreto. Que la expansión ficcional no sea cosa solo de los productores "corporativos", sino también de

\footnotetext{
1 Francele Mayor Mayor es Máster en Comunicación e Industrias Creativas en la Universidad de

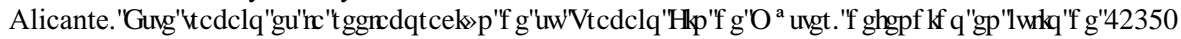


los fans implicados. "Si los viejos consumidores se suponían pasivos, los nuevos consumidores son activos. Si los viejos consumidores eran predecibles y permanecían donde les decías que se quedasen, los nuevos consumidores son migratorios y muestran una dudosa lealtad hacia las cadenas, las redes y los medios. Si los viejos consumidores eran individuos aislados, los nuevos consumidores están más conectados socialmente. Si el trabajo de los consumidores mediáticos fue antaño silencioso e invisible, los nuevos consumidores son hoy ruidosos y públicos" (Jenkins, 2008:29).

Jenkins considera que la colaboración entre el público es esencial para entender la historia completa. No se limita aquí su función, ya que fomenta la participación en la historia que se cuenta e incluso invita a los usuarios a trabajar sobre elementos de la historia, desarrollados puntual o extensamente. De esta manera, se involucran y ofrecen sus propias especulaciones, dando lugar a una ampliación no autorizada de estas franquicias de medios en nuevas direcciones, que reflejan el deseo del lector para 'llenar los vacíos' que han descubierto en el material producido (Jenkins, 2007).

Aparte de Jenkins, conviene también precisar la opinión de otros expertos en la materia. Carlos Alberto Scolari señala que "uno de los rasgos distintivos de las narrativas transmediáticas es precisamente la expansión del relato por medio de la incorporación de nuevas situaciones y personajes" (Scolari, 2011).

Añade que "el fantasma de las narrativas transmediáticas (transmedia storytelling) recorre los estudios de comunicación. Desde la incorporación de este concepto por parte de Jenkins (2003), numerosos investigadores y centros de estudio han incorporado a las narrativas transmediáticas dentro de su agenda de trabajo. Estos relatos que se expanden a través de múltiples medios y plataformas con la complicidad de sus receptores -ahora reconvertidos en prosumidores- se han posicionado como uno de los objetos de investigación más atrayentes de la era de la convergencia. Investigadores provenientes de diferentes áreas del saber se han ido acercando a un objeto de estudio multidisciplinar, por momentos ilimitado y en permanente mutación, lo que dificulta su focalización científica" (Scolari, C.A., Jiménez, M., y Guerrero, M., 2012:138).

Por otro lado, Jeff Gomez, director ejecutivo de Starlight Runner Entertainment, enumera ocho características que definirían una narración transmedia, y que -dicho sea de paso- difícilmente hallaremos en una ficción nacional. Por ejemplo, que la transmedialidad se prevea al principio de la vida de la franquicia o que el contenido se distribuya en tres o más plataformas son rasgos que incumplen la mayoría de las producciones nacionales. También suponen restricciones añadidas que el contenido haya de ser concebido por uno o pocos visionarios; que haya de ser único, que tenga que adherirse a las fortalezas específicas de la plataforma y no se haya de reutilizar de una plataforma a otra y que deba basarse en una visión única para el mundo de la historia.

Asimismo, señala que es necesario un impulso concertado para evitar fracturas y escisiones; se requiere un esfuerzo vertical a través de la empresa, terceros y concesionarios $\mathrm{y}$, finalmente, el conjunto necesita, para fraguar convenientemente, recursos de participación del público (web, redes sociales e historia vehiculada por contenidos generados por los usuarios) (Gómez, 2007). 
Finalmente, Rodríguez Ferrándiz considera que "ya no son meras adaptaciones o transposiciones lo que tenemos: filmes que proceden de novelas o de cómics, series de televisión, cómics o novelas que proceden de filmes exitosos previos. Ni tampoco continuaciones que prolongan y serializan el producto, pero como una estrategia a posteriori y, digamos, advenediza. Más bien se trata de un contenido ficcional que nace y evoluciona inseminado ya en múltiples soportes y plataformas, alimentado por creadores profesionales y por fans amateurs, en ocasiones extraordinariamente activos y competentes, que crece de una manera que es a la vez enciclopédica e intrigante" (Rodríguez Ferrándiz, 2012:66).

Quizá habría que quedarse con la reflexión formulada por el propio Jenkins. Transmedia se ha convertido para una comunidad cada vez mayor de artistas, narradores, marcas, diseñadores de juegos y críticos/investigadores en una causa motriz en sus vidas creativas e intelectuales.

No hay unanimidad en la definición de narración transmedia pero, por otro lado, tampoco hay acuerdo sobre que ese término sea el más idóneo para definir el fenómeno del que hablamos. Frank Rose, por ejemplo, habla de deep media y Christy Dena o Drew Davidson de cross-media. Ahora bien, como reconoce Jenkins, y por encima de los desacuerdos de matiz, el fenómeno de la trasmedialidad en los productos de entretenimiento es cada vez más importante en los debates acerca de cómo los medios operan en la era digital, y nos obligan a trascender tanto los modelos específicos de negocio de cada medio de entretenimiento como -y es lo que nos interesará aquí- los relatos contenidos en cada medio o soporte singular, para abordarlos en cambio desde una perspectiva transmedial (2010:944).

El problema radica, tal y como expone Jenkins, en que se trata de un periodo de experimentación e innovación, en el que se busca todavía encontrar etiquetas y fórmulas de amplio consenso para estrategias novedosas, y en el que los nuevos modelos de creación, producción y distribución que están emergiendo coexisten con prácticas más tradicionales y acreditadas.

Finalmente, advierte de que no existe una fórmula transmedia. Transmedia se refiere a un conjunto de decisiones tomadas sobre la mejor manera de contar una historia en particular a un público en particular en un contexto determinado en función de los recursos específicos disponibles para los productores particulares. Cuanto más ampliemos la definición, más rica será la gama de opciones disponibles para nosotros. Esto no quiere decir que transmedia, y narración transmedia más en particular, pueda ser cualquier cosa. Significa que necesitamos una definición para excluir los proyectos que no están explorando el potencial de expansión transmedia, sino que simplemente se cuelgan la etiqueta transmedia; pero que llevan a cabo las mismas viejas prácticas de franquicias que hemos visto durante décadas (Jenkins, 2011).

\section{METODOLOGÍA}

Para el desarrollo del trabajo empírico se ha escogido la técnica cualitativa del estudio de caso, que ha sido aplicada a los proyectos transmedia de la cadena Antena 3. El punto de partida de esta investigación ha sido la enunciación de algunas de las 
teorías más relevantes sobre el transmedia storytelling, que permitirán una adecuada acotación de las producciones transmedia y una valoración ajustada de su novedad.

A continuación, se abordarán las cuatro series seleccionadas. Se explicará por qué son transmedia, cuáles son sus limitaciones y deficiencias, dónde reside su éxito, la dimensión temporal de las estrategias transmedia respectivas y por qué se han elegido estas y no otras.

Seguidamente, para obtener una perspectiva más ajustada del transmedia storytelling, se apuntarán algunos elementos que permitan comparar las series españolas y las norteamericanas, en relación con las estrategias transmedia respectivas. En este punto se podrá advertir cuáles son las fortalezas y las debilidades de la expansión ficcional en la producción televisiva española.

Pero antes hemos de justificar brevemente por qué hemos elegido la cadena privada Antena 3 para acotar nuestro estudio. Algunos trabajos apuntan a que dicha cadena ha sido, de entre las españolas, la que mejor ha entendido la transmedialidad y la más implicada en la difusión de los contenidos en la Red. "Es el grupo televisivo que más ha apostado por las nuevas tecnologías, el primero en emitir su señal en directo vía móvil, en tener un canal propio en Youtube y en el preestreno de sus productos tanto por Internet como por el móvil" (Lacalle, 2011:96).

Un avance tecnológico destacado, que esta cadena impulsó en mayo de 2009, fue "el lanzamiento de televisión 3.0, coincidiendo con el estreno de la quinta temporada de la popular serie de Globomedia El Internado. 3.0. Este avance incrementa considerablemente tanto la retroalimentación entre televisión e Internet como la interactividad entre la televisión y el espectador e implica la conversión de la cadena tradicional en un operador global y multisoporte de contenidos, integrado por los tres canales de la cadena privada (Antena3, Neox y Nova) y por los tres soportes de difusión televisiva (televisión, internet y móvil). La interconexión de canales y soportes 3.0 permite la difusión múltiple de sus productos estrella, pero integrados con herramientas y contenidos adicionales exclusivos adecuados a los diferentes canales y soportes" (Lacalle, 2011:98). Ello se viene aplicando a series recientes de la cadena, como El barco, Amar es para siempre o Gran Hotel. Pero como veremos, Antena 3 fue pionera, antes incluso de la web 2.0, en la implementación de estrategias de expansión de sus relatos seriales televisivos a otros medios y plataformas.

Por tanto, nos encontramos ante una televisión pionera, conjuntamente con RTVE, que apuesta por la novedad, la innovación, la tecnología y, sobre todo, la transmedialidad. En el polo opuesto, se sitúa la otra gran cadena nacional, Telecinco, que se caracteriza por seguir los parámetros de la televisión más convencional.

\section{COMPANEEROS}

Fue una serie semanal en prime time que se emitió en Antena 3 entre 1998 y 2002, con nueve temporadas en total y con un éxito notable. Coincidió en antena con otras dos series de la cadena privada rival, Médico de familia y Periodistas (Telecinco), de temáticas distintas, así como con un serial diario en horario de sobre- 
mesa también de Telecinco, Al salir de clase, que sí abordaba un tema similar, aunque desde una perspectiva distinta. Su productora fue Globomedia y el guión y la dirección corrieron a cargo de Manuel Ríos San Martín. En este caso que nos ocupa se puede hablar, con ciertas reservas, de tres productos ficcionales transmediáticos: la serie, la película y las novelas.

Si bien es cierto que en los tres casos se produce una expansión del relato a través de la incorporación de nuevos personajes o situaciones, la realidad es que en este periodo todavía no había hecho su aparición la web 2.0. Este factor resulta determinante y nos invita a pensar que estamos ante una protonarrativa transmediática o simplemente ante un anticipo o una idea primeriza de lo que sucederá con posteridad.

Esta protonarrativa, como es obvio, se limitó a los formatos convencionales (novelas, cine y la propia serie). Por tanto, no pudo sacar partido de todas las potencialidades de la red tal y como la conocemos ahora. La ausencia de una participación activa de los usuarios (no hubo prácticamente contenidos generados por los mismos, user-generated content) es una de las principales carencias de estas producciones y, por este motivo, se hace difícil afirmar que son creaciones transmedia. Sin embargo, sí que se puede decir que cumplen con algunas características que definen las narrativas transmediáticas.

La serie narra las aventuras y desventuras de un grupo de jóvenes (encabezados por Quimi y Valle) que cursan el bachillerato en el Instituto Azcona. Inconsciencia e inocencia propia de la adolescencia aderezadas con turbulentas relaciones familiares y extraescolares. Amor y desamor. También trata temas tabú en la época pero más comunes hoy día como son el bullying, las drogas, los embarazos no deseados o la violencia de género. El reparto adulto de Compañeros -familiares y profesores- acaparan el papel más cómico pero también mezclan momentos de drama y conflictos.

Por su parte, el filme No te fallaré, estrenado en el receso entre la sexta y la séptima temporada de la serie, es la historia de los protagonistas de Compañeros, tres años después de terminar el instituto. La película comienza con los alumnos del Azcona en la fiesta de celebración por la conclusión de sus estudios. Todos deciden ir a una playa, en donde Quimi descubre que hay una especie de acantilado, del cual decide lanzarse, seguido poco después por sus compañeros. César resbala y cae sobre una enorme boya de metal, quedando tetrapléjico. Ese hecho los marca y los tortura de manera permanente. A partir de aquí, la acción se sitúa tres años más tarde. La vida de los personajes ha cambiado completamente. Valle es gogó en una discoteca, Luismi ejerce de profesor en el colegio Azcona, Sara está embarazada y Quimi trabaja en un restaurante.

Los sucesos desencadenantes de la trama de No te fallaré no se reflejaron en la séptima temporada de la serie -que comenzó a emitirse solo mes y medio después del estreno de la película- sino que se retomaron en la octava y novena, originando, por consiguiente, significativos desajustes en la cronología interna del relato. La dirección y la productora es la misma en las dos creaciones, por tanto, se podría presuponer una planificación y coordinación previa que, sin embargo, a todas luces brilla por su ausencia.

Las incongruencias fueron básicamente dos. En primer lugar, la película se inicia con los alumnos celebrando que han terminado sus estudios, mientras que en la 
ficción televisiva todavía están en el instituto y no será hasta el último capítulo de la séptima temporada cuando obtengan las notas de selectividad.

Por otra parte, en el filme se muestra cómo César sufre un accidente y queda tetrapléjico pero, no obstante, en Compañeros el personaje en cuestión se encuentra en perfecto estado e incluso es el protagonista central de las tramas de los capítulos 3, 4, 6, 7, 8 y 9 de la séptima temporada. El eje argumental de las mismas gira en torno a la relación amorosa de César con Tanja y Arancha.

Las temporadas octava y novena, que ya guardan una coherencia temporal con No te fallaré, no llegar a presuponer que el espectador ha visto el filme, pero sí parecen ser congruentes con algunos sucesos mostrados en éste, y que en la serie son referidos indirectamente. Son varios los capítulos de la octava temporada que abordan el asunto del accidente de César y el proceso de recuperación del coma hasta la salida del hospital (capítulos 2, 3, 8 y 9). Su padre se desentiende y le abandona en un hotel; Luismi se hace cargo de él y de su ingreso en un centro de rehabilitación. Sus notables progresos son también sucesos que tienen a César como protagonista (episodios 11, 12 y 14). En la siguiente temporada, la última de la serie, César ya no acapara tanto protagonismo. Únicamente reaparece en el capítulo 12 cuando regresa al colegio.

El otro producto transmediático es la colección de seis novelas editadas por Salvat que incorporaban argumentos nuevos. A diferencia de lo que sucedía con la película, no había una conexión entre las tramas de la serie y las de las novelas, de manera que cabe suponer una mayor independencia creativa de los autores, frente a la sintonía narrativa que garantizaba, en la serie y el filme, que los guiones fueran obra de la misma persona.

En la siguiente tabla se esboza el encadenamiento temporal de las creaciones transmedia y también se plasma la cronología interna, al ser esta franquicia un caso más problemático por presentar incongruencias en su relato. 


\begin{tabular}{|c|c|c|c|c|}
\hline & SERIE & PELÍCULA & NOVELAS & $\begin{array}{l}\text { CRONOLOGÍA } \\
\text { INTERNA }\end{array}$ \\
\hline $\begin{array}{l}1998-2000 \\
1^{\mathrm{a}} \text { temporada } \\
(25 / 03 / 98 \text { a } \\
19 / 06 / 98) . \\
2^{\mathrm{a}} \text { temporada } \\
(16 / 09 / 98 \text { a } \\
16 / 12 / 98) . \\
3^{\mathrm{a}} \text { temporada } \\
(03 / 03 / 99 \text { a } \\
02 / 06 / 99) . \\
4^{\mathrm{a}} \text { temporada } \\
(15 / 09 / 99 \mathrm{a} \\
13 / 12 / 99) . \\
5^{\mathrm{a}} \text { temporada } \\
(17 / 04 / 00 \mathrm{a} \\
12 / 07 / 00) .\end{array}$ & $\begin{array}{l}\text { Compañeros } \\
\text { Temporadas } \\
1^{\mathrm{a}} \text { a } 5^{\mathrm{a}}\end{array}$ & & & $\begin{array}{l}\text { Primeros años de los } \\
\text { alumnos del Azcona. }\end{array}$ \\
\hline Septiembre 2000 & & & $\begin{array}{l}\text {-César y Tanja } \\
\text { detectives privados. } \\
\text {-Tus problemas son } \\
\text { nuestros problemas } \\
\text {-Quimi contra la } \\
\text { mafia } \\
\text {-El guardián del } \\
\text { bosque, } \\
\text {-Todos a una } \\
\text {-Sara en peligro. }\end{array}$ & \\
\hline $\begin{array}{l}6^{\mathrm{a}} \text { temporada } \\
(19 / 09 / 00 \mathrm{a} \\
12 / 12 / 00) .\end{array}$ & $\begin{array}{l}\text { Compañeros } \\
6^{\mathrm{a}} \text { temporada }\end{array}$ & & & \\
\hline $\begin{array}{l}2 \text { de marzo de } \\
2001\end{array}$ & & No te fallaré. & & $\begin{array}{l}\text { Finalizan sus estudios. } \\
\text { César tiene un } \\
\text { accidente y queda } \\
\text { tetrapléjico. Tras estos } \\
\text { sucesos, la acción se } \\
\text { sitúa tres años más } \\
\text { tarde. }\end{array}$ \\
\hline $\begin{array}{l}7^{\mathrm{a}} \text { temporada } \\
(17 / 04 / 01 \mathrm{a} \\
10 / 07 / 01) .\end{array}$ & $\begin{array}{l}\text { Compañeros } \\
7^{\mathrm{a}} \text { temporada }\end{array}$ & & & $\begin{array}{l}\text { Curso previo al verano } \\
\text { donde sucede el } \\
\text { accidente. César se } \\
\text { encuentra } \\
\text { perfectamente. }\end{array}$ \\
\hline $\begin{array}{l}8^{\text {a }} \text { temporada } \\
(19 / 09 / 01 \text { a } \\
18 / 12 / 01) . \\
9^{\mathrm{a}} \text { temporada } \\
(23 / 04 / 02 \text { a } \\
23 / 04 / 02) .\end{array}$ & $\begin{array}{l}\text { Compañeros } \\
8^{\mathrm{a}} \text { y } 9^{\mathrm{a}} \\
\text { temporadas }\end{array}$ & & & $\begin{array}{l}\text { Nueva pandilla en el } \\
\text { Azcona. César está en } \\
\text { coma, y al despertar le } \\
\text { quedan secuelas en } \\
\text { forma de tetraplejia. El } \\
\text { accidente no ocurre en } \\
\text { la ficción, sino que las } \\
\text { imágenes que aparecen } \\
\text { proceden de los } \\
\text { recuerdos de Luismi en } \\
\text { forma de flashback. }\end{array}$ \\
\hline
\end{tabular}

Valga esta protonarrativa transmediática para constatar que en ese periodo ya hay series que presentan algunos rasgos de las estrategias transmedia. Las ficciones que serán objeto de estudio a continuación se ubican en cambio en la actualidad, y se aprecia en ellas un transmedia storytelling ya más maduro y con posibilidades tecnológicas plenas para integrar la participación del espectador.

Pero antes de profundizar en la investigación de las mismas, corresponde citar otros productos ficcionales serializados de Antena 3 comprendidos entre los años 2002 y 2010: Un paso adelante (2002-2005), Aqui no hay quien viva (2003-2006), Mis adorables vecinos (2004-2006), Los hombres de Paco (2005-2010), El Internado (2007-2010), Física o Química (2008-2011) o Doctor Mateo (2009-2011) son algunas ficciones representativas de este periodo.

Como aspecto significativo cabe advertir la ausencia de transmedia storytelling en las cuatro primeras. Son años donde todavía no se había consolidado este fenómeno. A partir de El Internado ya se observan las primeras expansiones ficcionales. Y así, el videojuego El Internado para Nintendo DS incluía un gran número de con- 
tenidos extras, argumentos paralelos y nuevos guiones diferentes a la ficción. La novela Misterio en el Zurbarán presentaba una trama completamente inédita, nunca vista en Física o Química. Por último, la novela Doctor Mateo: Tres veranos en San Martín narraba hechos que sucedieron mucho antes de la época en que transcurría la serie, los tres veranos que Mateo pasó en el pueblo cuando era niño junto con su abuelo y su tía Juana, constituyendo por tanto una precuela bastante diferida de la serie en sí.

\section{LOS PROTEGIDOS}

Es una serie producida por Boomerang TV para Antena 3. Esta producción de ficción se emitió en tres temporadas entre 2010 y 2012. La serie cuenta las peripecias de los Castillo Rey, una peculiar familia que huye de una extraña organización que los busca y que tiene secuestrada a su hija Blanca. Se les persigue porque muchos de sus componentes poseen poderes sobrenaturales, que ahora deben ocultar.

Una vez concluida la segunda temporada, Antena 3 lanzó en septiembre de 2011 el videojuego Los protegidos, concebido para Ipod y Ipad. Esta aventura gráfica presentaba un argumento que, aunque basado en la serie, era totalmente novedoso. El juego constaba de nueve episodios. En cada uno se podía seleccionar uno de los protagonistas de la ficción, reproducir las historias de los personajes e interactuar con los lugares y objetos más característicos. Posteriormente, también se creó una aplicación del juego en Facebook. En esta red social se podía compartir contenidos con otros usuarios y tener acceso a los episodios de la serie.

Una semana después del lanzamiento del videojuego apareció una colección de tres novelas que incorporaban tramas nuevas. Al igual que sucedía en Compañeros, no había una conexión entre las tramas de la serie y las de las novelas. En la misma editorial, de las novelas, Montena, apareció en ese momento un Diario Oficial de la serie, con imágenes y datos inéditos, juegos, tests y curiosidades sobre la familia Castillo Rey y los demás protagonistas de la serie. Finalmente, y coincidiendo con el estreno de la tercera temporada de la producción, se lanzó la aplicación Ant3.0, que permitía a los fans disfrutar de contenidos exclusivos como vídeos o fotografías. Además de recibir contenidos, el usuario podía interactuar. La aplicación no sólo proporcionaba productos audiovisuales, sino que también enlazaba a páginas de internet (Facebook, Twitter...) relacionadas con la serie. En esta ocasión, la novedad es que el disfrute de la expansión transmediática se hacía al mismo tiempo. La experiencia del espectador frente a la pantalla pasaba a ser interactiva. Por otra parte, los propios fans de Los protegidos también se suman a la creación de sus propias historias, una vez concluida la última temporada ${ }^{2}$.

Recogemos de nuevo en una tabla el encadenamiento temporal que se produce entre los productos transmedia de Los protegidos.

\footnotetext{
2 En el siguiente enlace se puede leer un argumento no corporativo del primer capítulo de la cuarta temporada producido por un fan: http://www.formulatv.com/series/los-protegidos/foros/5310/1/los-protegidosla-caida-de-los-castillo-rey-t4/
} 


\begin{tabular}{|l|l|l|l|l|}
\hline & SERIE & ANT3.0 & VIDEOJUEGO & NOVELAS \\
\hline $\begin{array}{l}1^{\mathrm{a}} \text { temporada } \\
(12 / 01 / 10 \mathrm{a} \\
12 / 04 / 10) .\end{array}$ & Los protegidos & & & \\
\hline $\begin{array}{l}2^{\mathrm{a}} \text { temporada } \\
(16 / 01 / 11 \mathrm{a} \\
17 / 04 / 11) .\end{array}$ & Los protegidos & & & \\
\hline $\begin{array}{l}\text { Septiembre de } \\
2011\end{array}$ & & & $\begin{array}{l}\text { Lanzamiento del } \\
\text { videojuego Los } \\
\text { protegidos. }\end{array}$ & \\
\hline $\begin{array}{l}15 \text { de septiembre } \\
\text { de 2011 }\end{array}$ & & & & $\begin{array}{l}\text {-Para siempre } \\
\text { Angel } \\
\text {-Ni contigo ni sin } \\
\text { ti. }\end{array}$ \\
\hline $\begin{array}{l}3 \text { de noviembre de } \\
2011\end{array}$ & & & $\begin{array}{l}\text {-A por todas } \\
\text { Lucas. } \\
\text {-Diario Oficial de } \\
\text { Los Protegidos }\end{array}$ \\
\hline $\begin{array}{l}3^{\mathrm{a}} \text { temporada } \\
(08 / 03 / 12 \text { a } \\
13 / 06 / 12) .\end{array}$ & Los protegidos & $\begin{array}{l}\text { Ant3.0 } \\
\text { Empleo de la } \\
\text { aplicación en la } \\
\text { serie. }\end{array}$ & & \\
\hline
\end{tabular}

\section{EL BARCO}

Es una serie producida por Globomedia para Antena 3. Esta producción nacional se emitió en tres temporadas entre 2010 y 2013. El creador, productor ejecutivo y guionista fue Daniel Écija, responsable también de algunas de las teleseries más famosas de la televisión española, desde Médico de familia (T5, 1995-1999), Periodistas (T5, 1998-2002), Un paso adelante (A3, 2002-2005), Los Serrano (T5, 2003-2008) o Los hombres de Paco (A3, 2005-2010) a El internado (A3, 20072010) o Aguila Roja (TVE1, 2009-), así como productor ejecutivo de No te fallaré (2001), la extensión transmedial cinematográfica de Compañeros. La ficción transcurre en un buque-escuela, el Estrella Polar, en el que se van a embarcar varias personas para formarse. Una tormenta descomunal deja al barco perdido en mitad del océano. Se mantiene a flote, pero todos los sistemas de localización quedan averiados por los rayos. La científica Julia Wilson investiga el fenómeno y llega a la conclusión de que pueden ser los únicos habitantes de la Tierra. Además de este suceso trascendental, los habitantes del barco vivirán numerosas historias a bordo.

Los twittersodios de la serie ejemplifican otro producto ficcional. Cabe advertir que su estreno es anterior incluso a la misma ficción televisiva. Recreaban el universo de El Barco en Twitter y permitían a los fans participar en él durante la hora previa a la emisión de cada episodio en televisión. Los twittersodios complementaban la trama, proporcionaban pistas adicionales y mejoraban la experiencia global de los telespectadores que conversaban directamente con los personajes (se habían creado 14 perfiles en la red social de los protagonistas de la serie). De este modo, se generaba una conexión más estrecha entre los televidentes y los propios personajes.

De hecho, uno de los logros que se pueden resaltar de esta serie ha sido, sin lugar a dudas, los twittersodios: \#ElUltimoBarco obtuvo un éxito considerable, alcanzado el $97,34 \%$ del share social, con más de 200.000 comentarios y 82.898 espectadores sociales. A las 00:39 del 22 de febrero de 2013, momento del cierre dell último episodio, el twitter de la serie consiguió el minuto de oro con 4.393 comentarios por 
minuto, coincidiendo con el momento en el que Ainhoa se dispone a casarse con Ulises, según datos de la propia Antena $3^{3}$.

El último capítulo de $E l$ Barco logró además un buen número de trending topics nacionales (\#ElUltimoBarco, El Barco, Mario Casas, Gamboa, Burbuja, Valeria, Ulises y Ainhoa, Vilma) y mundiales (\#ElUltimoBarco, El Barco, Ulises, Piti, Gamboa).

En la tabla siguiente se recogen las cuentas de Twitter de los personajes, el número de tuits realizados por cada protagonista, el número de seguidores que tienen en la actualidad, el número de seguidores que poseían cuando finalizó la emisión del último twittersodio, coincidiendo con el último capítulo de la segunda temporada, y, además, se incluye la fecha exacta en que finalizó su actividad en esta red social.

\begin{tabular}{|c|c|c|c|c|}
\hline Cuentas twitter & Tuits & $\begin{array}{l}\text { Seguidores } \\
\text { actuales }\end{array}$ & $\begin{array}{l}\text { Seguidores en el } \\
\text { último } \\
\text { twittersodio }^{1}\end{array}$ & Dejó de twittear \\
\hline @tlmaco & 1.086 & 24.569 & 27.039 & 24 de noviembre de 2011 \\
\hline @JuliaCWilson & 515 & 14.442 & 16.249 & 5 de enero de 2012 \\
\hline @cap_montero & 710 & 12.391 & 14.617 & 5 de enero de 2012 \\
\hline @ainhoa_89 & 689 & 21.375 & 25.761 & 24 de noviembre de 2011 \\
\hline @YoBurbuja & 427 & 17.830 & 21.847 & 27 de enero de 2012 \\
\hline @just_vilma & 663 & 16.584 & 20.111 & 22 de diciembre de 2011 \\
\hline @palomar_es & 691 & 14.858 & 18.272 & 1 de diciembre de 2011 \\
\hline @esecachodepiti & 1.331 & 18.669 & 22.658 & 5 de enero de 2012 \\
\hline @stlademar & 439 & 14.479 & 13.202 & 5 de enero de 2012 \\
\hline (a)ramlocke & 482 & 9.918 & 11.874 & 5 de enero de 2012 \\
\hline @L_Gmboa & 313 & 9.983 & 11.750 & 5 de enero de 2012 \\
\hline @dlcuadra & 433 & 10.449 & 12.692 & 5 de enero de 2012 \\
\hline @Salo_Mar & 341 & 10.711 & 12.275 & 5 de enero de 2012 \\
\hline
\end{tabular}

Podemos, por tanto, concluir diciendo que Twitter, Facebook, Tuenti, MySpace o los emails permiten crear una relación directa entre los personajes y los espectadores. Ellos eligen lo que quieren mostrar, cómo y para quién. Es mejor contar una historia íntima o una confesión a través de medios interactivos que por televisión tradicional. El resultado es una gratificación para un consumidor fiel, el que más merece confidencias de los personajes.

Al finalizar la primera temporada, y probablemente con el objetivo de proseguir la promoción de la serie, Antena 3 lanzó un reality show El barco: Rumbo a lo desconocido basado en la ficción. El fracaso de este programa fue rotundo, a diferencia de la estrategia en Twitter. La conexión entre el reality y la ficción era más que evi-

3 Información recogida del siguiente enlace: http://blogs.antena3.com/socializados/barco-despide-consiguiendo-share-social_2013022200002.html

${ }^{4}$ Los datos de los followers del último twittersodio proceden de "Transmedia audiences and television fiction: A comparative approach between Skins (UK) and El Barco (Spain)". Journal of Audience \& Reception Studies. Volume 9, Issue 2, 569-570. 
dente. La expedición estaba formada por 14 concursantes y, al igual que sucedía en la serie, estaban aislados del resto del mundo y no tenían contacto con la civilización. Del mismo modo que el Estrella Polar tenía su capitán, en El barco: Rumbo a lo desconocido también había un líder, que decidía no solo la travesía por la que navegaban, sino que era clave en la formación de los participantes y decidía los dos concursantes que se batirían en duelo para permanecer tres días más en el juego.

Como en el caso anterior, Antena 3 también creó el videojuego oficial de El Barco. Se lanzó unas semanas después de que se iniciara la emisión de la segunda temporada de la serie. Se trata de un juego de estrategia multijugador en el que cada usuario es el capitán de su embarcación. Debe hacerla crecer y formar una tripulación consistente que le permita competir con el resto de participantes. Las tramas de la serie tienen continuidad en el juego. Al finalizar cada episodio, se activa una nueva misión en la web que discurre en torno a lo que se acaba de emitir en televisión. Cada jugador, que actúa como capitán de su propio barco, debe resolver dicha misión para avanzar en el juego. Los personajes de El Barco también forman parte del juego, ya que cada uno tiene su propio espacio. Los usuarios se encuentran con los tripulantes del Estrella Polar en diferentes lugares y momentos.

Al igual que sucedía en Los protegidos, el uso de la aplicación Ant3.0 también se extendió a $E l$ Barco durante su tercera temporada. De esta manera, los usuarios podían acceder a vídeos o información exclusiva de la ficción. Por otra parte, se permitía que los fans crearan sus propias historias 5 . Hay usuarios que incluso fueron capaces de crear sus propias versiones del conocido videojuego Sims, pero con la particularidad de que los personajes eran los protagonistas de su serie preferida, El Barco ${ }^{6}$.

En la tabla siguiente se plasma la relación temporal de los distintos productos transmedia.

\begin{tabular}{|c|c|c|c|c|c|}
\hline & SERIE & TWITTERSODIOS & REALITY & ANT3.0 & VIDEOJUEGO \\
\hline 13 de enero & & $\begin{array}{l}\text { \#ElUltimoBarco } \\
\text { Su estreno fue anterior } \\
\text { al de la ficción. Se } \\
\text { cancelaron al concluir } \\
\text { la } 2^{\mathrm{a}} \text { temporada. }\end{array}$ & & & \\
\hline $\begin{array}{l}1^{\text {a }} \text { temporada } \\
(17 / 01 / 11 \text { a } \\
25 / 04 / 11) .\end{array}$ & $\begin{array}{l}\text { El } \\
\text { Barco }\end{array}$ & & & & \\
\hline $\begin{array}{l}19 \text { junio de } \\
2011 \text { al } 11 \text { de } \\
\text { septiembre }\end{array}$ & & & $\begin{array}{l}\text { El barco: Rumbo } \\
\text { a lo desconocido }\end{array}$ & & \\
\hline $\begin{array}{l}2^{\mathrm{a}} \text { temporada } \\
(08 / 09 / 11 \text { a } \\
05 / 01 / 12)\end{array}$ & $\begin{array}{l}\text { El } \\
\text { Barco }\end{array}$ & & & & $\begin{array}{l}\text { Lanzamiento del } \\
\text { videojuego } E l \\
\text { Barco. }\end{array}$ \\
\hline $\begin{array}{l}3^{\mathrm{a}} \text { temporada } \\
(18 / 10 / 12 \mathrm{a} \\
21 / 02 / 13) .\end{array}$ & $\begin{array}{l}\text { El } \\
\text { Barco }\end{array}$ & & & $\begin{array}{l}\text { Ant3.0 } \\
\text { Empleo } \\
\text { de la } \\
\text { aplicación } \\
\text { en la } \\
\text { serie. }\end{array}$ & \\
\hline
\end{tabular}

5 Véase el siguiente enlace: http://www.formulatv.com/series/el-barco/foros/3227/1/quereis-saber-elfinal-de-esta-serie/

6 En el siguiente link se puede apreciar el vídeo elaborado por los fans: $\mathrm{http}: / /$ www.youtube.com/watch?v=WFLeNok0sSc\&feature=youtu.be 


\section{HISPANIA, LA LEYENDA}

Es una serie de Antena 3 producida por Bambú. Esta ficción nacional, que contó con tres temporadas, se emitió entre 2010 y 2012. Se ambientó en la Península Ibérica durante el siglo II a. C. y el creador fue Ramón Campos. La serie es un drama histórico que narra el período en el que los lusitanos, con Viriato a la cabeza, se enfrentan a los romanos encabezados por Galba para defender su territorio, Hispania.

El juego surgió antes de que se estrenara la serie. Su lanzamiento tuvo lugar durante el rodaje de la primera temporada. Sus personajes están basados en los protagonistas de la misma y el usuario puede convertirse en un personaje más, hispano o romano, y comenzar a construir su propia civilización. A lo largo del juego los usuarios son asesorados por algunos de los protagonistas de la serie. Las tramas de la serie tienen continuidad en el juego. Al finalizar cada episodio, se activa una nueva misión en la web que discurre en torno a lo que se acaba de emitir en televisión.

Por último, cabe señalar que la interacción entre el videojuego y la serie es evidente. El visionado del capítulo ayuda a resolver algunas pruebas del juego, mientras que el videojuego puede desvelar aspectos relevantes de la trama. Por tanto, es recomendable ver el capítulo antes de iniciar la misión.

Como ejemplo podemos mencionar una misión del videojuego que se corresponde al último episodio de la segunda temporada, El intercambio. En sintonía con el argumento desarrollado en la ficción, si en el juego eres romano verás que Galba monta en cólera ante la huida de Claudia con Fabio, no sólo por este hecho sino porque queda al descubierto la existencia de un traidor en las filas romanas. Marco es designado personalmente por Galba para que la busque y encuentre.

En el videojuego se fijan dos etapas. En la primera, por orden de Marco, se realiza una batida en el campamento para dar con el traidor que dio acceso a los hispanos. En la segunda, Claudia ha sido atrapada por los hispanos gracias a la traición de Fabio, pero el usuario cuenta con el hijo de Viriato para negociar un intercambio. Para evitar una trampa, Galba le pide al jugador que monte guardia en las inmediaciones con un ejército.

Por el contrario, si eres hispano, cuentas con Claudia a tu favor. A la hora de negociar un intercambio con los romanos se han establecido también dos etapas. En la primera, Héctor se ha infiltrado entre los romanos pero ha levantado sospechas y Marco está en busca del espía hispano. La función del usuario es maniobrar por medio de recursos para evitar la captura. En la segunda, es el momento de usar a Claudia como elemento de negociación en un intercambio por Serbal, hijo de Viriato. El usuario que participa en las misiones, además de involucrarse en las tramas de la serie, logra una recompensa en denarios y puntos cuando la completa.

Por otra parte, cabe añadir otra creación transmedia: la novela La fuerza del pasado, de Miguel Fernández, pero basada en la idea original de Ramón Campos, el guionista de la serie. El mismo día que concluía la segunda temporada se ponía a la venta este libro, ambientado entre 150 y 115 a.C. La novela, publicada por Singular Ediciones, narra, desde la mirada de Tirso, los hechos que sucedieron antes, duran- 
te y después de las fechas en las que transcurre la serie, entrelazados a modo de flashbacks.

Cada capítulo avanza o retrocede de una época a otra. Se mezcla el presente del narrador (Tirso de viejo) y el pasado (el inicio de la trama narrada en la serie Hispania, vista desde su percepción). De esta manera, el libro complementa y amplía los relatos y hechos de los episodios de televisión. Desvela parte del pasado de Viriato, ya que revela el motivo por el cual la familia de Viriato y Bárbara se fueron a Caura.

Al igual que sucedía en las dos ficciones anteriores, también hubo user-generated content ${ }^{7}$.

Finalmente, en la siguiente tabla se puede apreciar las principales conexiones temporales entre las creaciones transmediáticas.

\begin{tabular}{|l|l|l|l|}
\hline & SERIE & JUEGO & NOVELAS \\
\hline Julio de 2010 & & $\begin{array}{l}\text { Lanzamiento del } \\
\text { videojuego Hispania. }\end{array}$ & \\
\hline $\begin{array}{l}\text { 2010-2011 } \\
1^{\text {a temporada }(25 / 10 / 10} \\
\text { a 11/01/11). }\end{array}$ & Hispania & & \\
$2^{\mathrm{a}}$ temporada (10/05/11 & & & \\
a 28/06/11). & & & \\
\hline 28 de junio de 2011 & & & La fuerza del pasado. \\
\hline $\begin{array}{l}3^{\mathrm{a}} \text { temporada (11/06/12 } \\
\text { a 25/06/12). }\end{array}$ & Hispania & & \\
\hline
\end{tabular}

\section{CONCLUSIONES}

En la elección de las series se ha optado por escoger una ficción a caballo entre el siglo pasado y este, Compañeros, donde se aprecian algunos rasgos de las estrategias transmedia, y otras tres, ya mucho más recientes, donde las estrategias transmedia están más implantadas o, por lo menos, deberían estarlo. Compañeros se enmarca dentro de un periodo donde todavía no había hecho su aparición la web 2.0. La manera de entender la comunicación en red era todavía muy precaria. Será a partir de 2004 cuando se produzca un incremento sustancial del papel del usuario, capaz de interactuar tanto con otros espectadores y fans de la narración ficcional, como con los productores y guionistas, los actores y hasta los personajes (Askwith, 2007). Por tanto, podíamos considerar esta serie como una protonarrativa transmediática.

Las otras tres pertenecen de lleno a una era donde proliferan las comunidades web, las aplicaciones, las redes sociales, las wikis, los blogs, etc. Aunque el muestrario de series de Antena 3 durante el periodo comprendido entre 2004-2013 es muy amplio, se han seleccionado estas tres porque representan una muestra significativa de extensión transmedial en un gran número de formatos.

Algunas estrategias transmedia se han demostrado exitosas (como los twittersodios de El Barco o el videojuego de Hispania), pero otras han sido un completo fracaso (como el reality El barco: Rumbo a lo desconocido o la novela La fuerza del

\footnotetext{
7 Véase el siguiente enlace: http://blog.hispaniaeljuego.com/index.php/category/relatos/
} 
pasado). Es decir, que la planificación transmedia necesita de un fino ajuste y cálculo, y no todas las acciones, los soportes y las plataformas transmediales son válidas. "Aunque la infraestructura tecnológica está lista, las perspectivas económicas son halagüeñas y el público está preparado, las industrias mediáticas no se han esmerado en la colaboración para producir experiencias transmediáticas convincentes" (Jenkins, 2008:111). Una mayor integración y coordinación es otra razón que explica el fracaso de unos productos y, en cambio, el éxito de otros de la misma franquicia.

Sin embargo, hay que tener presente que "los diferentes medios atraen a diferentes segmentos del mercado. El cine y la televisión probablemente tengan el público más diverso; los cómics y los videojuegos el más restringido" (Jenkins, 2008:102). La clave consiste en lanzar el contenido de forma diferente en los distintos medios y evitar la redundancia que origina un desinterés entre los aficionados y aboca al fracaso. Ya que en un mundo con muchas opciones de medios, los consumidores están optando por un número limitado de franquicias que ofrecen variedad y no repetición (Jenkins, 2003).

Nuestros productos transmedia todavía no aprovechan del todo su potencialidad y quizás un aspecto fundamental en el que hay que incidir es en incrementar todavía más la involucración de los consumidores. Tal y como indican Costa y Piñeiro, "debería apostarse por un rol todavía más activo para el espectador/usuario/ lector. Su papel en el devenir de la historia debe ser incrementado en aras de conseguir que la identificación y la implicación en la historia se transformen en una auténtica inmersión" (2012: 123).

Hemos de constatar, con Bonaut y Grandío, que la web corporativa se ha convertido en la matriz en torno a la que gira todo el contenido que despliegan las series ficcionales. Es el lugar especial donde los espectadores pueden encontrar todo el material transmedia junto y los espectadores pueden seleccionar el tipo de consumo multiplataforma que desean (Bonaut, J. y Grandío, Ma , 2012:572). Podemos, por tanto, decir que el fenómeno de expansión ficcional se está extendiendo cada vez con mayor fuerza entre las series de nuestro país. Todavía no ha alcanzado la presencia que tiene en las series norteamericanas pero cada vez se va generalizando más.

Estudios realizados estos últimos años sobre teleseries y seriales norteamericanos recientes han demostrado que las estrategias transmedia responden a una planificación minuciosa para su lanzamiento, a una dosificación muy efectiva de los productos transmediales sucesivos, a un control creativo centralizado y a un incentivo constante que promueve la participación del fan y que en su caso reorienta o fecunda la propia producción corporativa (Scolari, 2009:594-598; Bonaut, J. y Grandío, Mª 2012:560; Rodríguez Ferrándiz, 2012:70-76; Askwith, 2007:122-148).

Respecto al primer aspecto, en España se está mejorando mucho en este sentido en las producciones más recientes. Recordemos la perfecta coordinación previa entre el videojuego y la serie de Hispania o entre los twittersodios y El Barco. En cuanto al control de los tiempos, se puede decir que es correcto, aunque también que es mucho más sencillo de realizar. Esta afirmación se fundamenta en el hecho de que, cuando termina una temporada de una serie cualquiera, la antena y la productora en cuestión deciden lanzar la novela, la aplicación o el videojuego que creen 
oportuno. De esta manera, se aseguran mantener el interés del fan. Este control es fácil, ya que simplemente hay una extensión en uno o, como mucho, en dos soportes.

Otra diferencia que se puede apreciar entre el transmedia storytelling en España y en EE.UU. tiene que ver con los soportes utilizados. En España se prescinde, en la mayoría de los casos, de medios como los cómics, los mobisodes, los webisodes y los minisodes, que, por el contrario, en EE.UU. cuentan con un destacado protagonismo. Además, cabe añadir que la cantidad y la calidad de la información ofrecida por los sitios web de televisión en España es insuficiente e imprecisa. Es cierto que dichos sitios web oficiales se están utilizando no sólo para proporcionar información sobre el programa, sino también para ofrecer una experiencia multimedia al espectador: datos sobre actores, episodios, directores, guionistas y productores, fotos exclusivas de cada capítulo y avances en vídeos, eventos, secciones con la música y la moda que aparecen en el programa, juegos y aplicaciones para teléfonos, ordenadores, tablets, etc. Sin embargo, el aspecto más relevante de la estrategia de los sitios web es la creación de expectativas propiamente narrativas y/o lúdicas para el espectador, como sucede con los Alternate Reality Games, es decir, una especie de juego de rol que articula actividades dentro y fuera del espacio mediático y que propone misterios o enigmas que resolver a los participantes, de manera colaborativa, relativos a la trama ficcional (Scolari, 2013; Bonaut, J. y Grandío, Mª 2012:567). Y esa cuestión no se cuida lo suficiente en España.

Otro aspecto fundamental que se descuida en las series nacionales es la promoción de las mismas. Se recurre a las formas convencionales: premieres, avances en la cadena o en la página web. Por el contrario, se prescinde de una publicidad más innovadora, integrada de alguna manera en el propio universo narrativo transmedial, que no solo permita que los productos calen más en sus potenciales consumidores, sino que abra el apetito por productos que no iban dirigidos específicamente a ese nicho de mercado. Es evidente que la promesa de una experiencia ficcional más intensa puede despertar el interés por medios o plataformas que no formaban parte del menú de medios de cierto público tradicional de las teleseries. $\mathrm{Y}$ es evidente también que un público más joven, ajeno a los seriales en prime time, pueda recalar en la ficción televisiva atraído por el videojuego o por la fanfiction que prolifera en Twitter (Lacalle, 2012, 2013). Que la promoción del producto no se sienta, al menos en alguna medida, como una venta, como un discurso publicitario al uso, enfático, hiperbólico, como una especie de "prueba de producto" en forma de promo o tráiler tradicional, sino que se incardine más sutilmente con el arco narrativo, haciendo de la campaña de lanzamiento o de los recesos entre las temporadas ocasiones para prolongar y expandir la trama ficcional, sin dejar por ello de promocionarla. Ese es otro reto que tienen pendientes las narrativas transmediáticas televisivas de factura nacional.

\section{REFERENCIAS BIBLIOGRÁFICAS}

Askwith, I. (2007). "Television 2.0: Reconceptualizing TV as an Engagement Medium". B.A. Individualized Study (Technology, Media \& Culture) Gallatin School of Individualized Study New York University, 117-149. 
Bonaut, J. y Grandío, Ma (2012). "Transmedia audiences and television fiction: A comparative approach between Skins (UK) and El Barco (Spain)". Journal of Audience \& Reception Studies. $\quad$ Volume 9, Issue 2. http://www.participations.org/Volume\%209/Issue\%202/30\%20Grandio\%20Bonaut.pdf

Cascajosa Virino, C. y Herrero Bernal, B. (2009). "De Compañeros a No te fallaré: Manuel Ríos San Martín y la experiencia en la producción cinematográfica de Globomedia". En J. Marzal Felici y F. J. Gómez Tarín (eds.), El productor y la producción en la industria cinematográfica, Madrid, Editorial Complutense, 495-505.

Costa SÁNChez, C. Y PIÑEIRo OTERO, T. (2012). "Nuevas narrativas audiovisuales: multiplataforma, crossmedia y transmedia. El caso de Águila Roja (RTVE)”. Icono 14, Vol.10, No.2, 102-125. http://icono14.net/ojs/index.php/icono14/article/view/156

GómEZ, J. (2007). "8 defining characteristics of a trans-media production". http://pganmc.blogspot.com.es/2007/10/pga-member-jeff-gomez-left-assembled.html

Jenkins, H. (2003). "Transmedia Storytelling: Moving characters from books to films to video games can make them stronger and more compelling". Technology Review. http://www.technologyreview.com/Biotech/13052/?a=f

Jenkins, H. (2007). "Transmedia Storytelling 101", en Confessions of an Aca-Fan. http://henryjenkins.org/2007/03/transmedia_storytelling_101.html

JENKIns, H. (2008). Convergence Culture: La cultura de la convergencia de los medios de comunicación. Barcelona: Paidos.

Jenkins, H. (2009). "The Revenge of the Origami Unicorn: Seven Principles of the Transmedia Storytelling". http://henryjenkins.org/2009/12/the_revenge_of_the_origami_uni.html http://henryjenkins.org/2009/12/revenge_of_the_origami_unicorn.html

JENKINS, H. (2010). "Transmedia Storytelling and Entertainment: An annotated syllabus". Continuum: Journal of Media \& Cultural Studies. Vol. 24, no. 6, 943-958.

JENKINS, H. (2011). "Transmedia Storytelling 202: Further Reflections". http://henryjenkins.org/2011/08/defining_transmedia_further_re.html

LACALle, R. (2011). "La ficción interactiva: Televisión y Web 2.0”. Ámbitos, no. 20, 87-107.

LACALLE, R. (2012). "Género y edad en la recepción de la ficción televisiva", Comunicar $\mathrm{n}^{\circ}$ 39, vol. XX, 111-118.

http://www.revistacomunicar.com/index.php?contenido=detalles\&numero=39\&articulo=392012-13\&mostrar $=$ comocitar\&idioma $=$ es

LACALle, R. (2013). Jóvenes y ficción televisiva: construcción de identidad y transmedialidad. Barcelona: UOC.

RodríGUEz FERRÁNDIZ, R. (2012). "Sangre fresca publicitaria: True Blood y las transfusiones de la ficción”. Anàlisi. Monogràfic 2012: Audiovisual 2.0, 65-80. http://www.analisi.cat/ojs/index.php/analisi/article/view/m2012-rodriguez/m2012-rodriguez

ScOLARI, C. A. (2009). “Transmedia Storytelling: Implicit Consumers, Narrative Worlds, and Branding in Contemporary Media Production”. International Journal of Communication 3, 586-606.

http://www.ijoc.org/ojs/index.php/ijoc/article/view/477/336

ScOLARI, C.A. (2011). "Narrativas transmediáticas y adaptaciones: el caso Tintin". http://hipermediaciones.com/2011/11/10/narrativa-transmediatica-y-adaptaciones-elcaso-tintin/

Scolari, C.A., Jiménez, M., y Guerrero, M., (2012). "Narrativas transmediáticas en España: cuatro ficciones en busca de un destino cross-media", Comunicación y Sociedad XXV, I, 137-163

http://www.unav.es/fcom/comunicacionysociedad/es/articulo.php?art_id=409 


\title{
RESUMEN
}

El presente artículo pretende realizar una aproximación al fenómeno de la expansión narrativa desde las series televisivas producidas en España a otros productos culturales que orbitan a su alrededor. Este estudio se centrará en una cadena de televisión, Antena 3, y en cuatro series españolas emitidas por la misma: Compañeros, Los protegidos, El Barco e Hispania. Los objetivos principales que se procuran alcanzar son constatar que el transmedia storytelling está dando sus primeros pasos en España, describir las estrategias transmediales de una cadena española en varias de sus producciones y comparar dichas estrategias con otras de series norteamericanas. Finalmente, la elección de la cadena seleccionada quedará justificada a la luz del análisis y se propondrán fortalezas y debilidades.

Palabras clave: narración transmediática, transmedia storytelling, crossmedia, multiplataforma, usuario, fan, serie, Twitter, Facebook, blog, videojuego, aplicación, novela, película.

\section{Transmedia Storytelling in Spanish Fiction TV: Antena 3 Case Study}

\begin{abstract}
The current article aims to get a closer look at the phenomenon that is the fictional expansion from TV series produced in Spain to the other cultural products that surround them. This study will focus on a TV station, Antena 3, and on four Spanish TV series produced for the aforementioned station: Compañeros, Los protegidos, El Barco, and Hispania.

The primary objectives in this study are to confirm that transmedia storytelling is taking its first steps in Spain, to describe transmedia strategies in a TV station in some of its products, and to compare such strategies with those of other North American series. Finally, why this TV station was chosen will be justified during the analysis herein, and strengths and weaknesses of this decision will be discussed.
\end{abstract}

Keywords: transmedia narrative, transmedia storytelling, crossmedia, multiplataform, user, fan, series, Twitter, Facebook, blog, videogame, app, novel, movie. 